\title{
ÉTUDES SUR LE PORC
}

\author{
Recherches faites par J. DELORT-LAVAL et S. Z. ZELTER \\ Laboratoire de Recherches sur la Conservation et l'Efficacité des Aliments, \\ 16, rue Claude Bernard, Paris $V^{\mathrm{e}}$.
}

\section{MÉTHODE}

Nous avons déterminé chez le porc la digestibilité vraie et la valeur biologique des trois farines de harengs.

Ces farines constituent la seule source azotée du régime composé par ailleurs d'un mélange de substances ternaires, de vitamines et de minéraux, utilisés pour l'estimation des dépenses azotées endogènes.

Une première période expérimentale (I) a permis de déterminer les coefficients de digestibilité des trois farines et de maintenir le régime à un taux constant de $11,5 \%$ de matières azotées digestibles par $\mathrm{kg}$ de matière sèche ingérée (soit $100 \mathrm{~g} \mathrm{de} \mathrm{m}$. a. d. par unité fourragère) au cours des trois périodes suivantes (II, III, IV) de mesure de la valeur biologique. Celle-ci est effectuée selon le principe des régimes tournants, pour réduire l'influence des facteurs animal et période.

6 porcs sont utilisés simultanément, dont le poids évolue entre les périodes II et IV de 50 à $80 \mathrm{~kg}$. La période d'estimation des dépenses endogènes s'intercale entre les périodes I et II; elle est suivie de vingt jours de réplétion azotée pour permettre le rétablissement d'un catabolisme azoté normal.

\section{RÉSULTATS}

Les résultats de l'expérience sont résumés dans le tableau 1.

\section{DISCUSSION}

Les coefficients d'utilisation digestive vraie sont pratiquement similaires pour les trois produits $((95,4-94,7-94,5)$. Il ne semble donc pas que l'intensité du chauffage, dans les limites où elle a été réalisée, ait eu une action sur la digestibilité des protéines. Étant donné, la longue durée de l'essai, les valeurs biologiques sont plus délicates à interpréter : en effet, l'influence de la période, due à l'évolution des besoins azotés spécifiques du porc en fonction de l'âge, est nettement plus importante que celle des conditions technologiques. Les moyennes des valeurs biologiques des 3 produits se révèlent très proches les unes des autres $(60,0-61,3-61,6)$; un calcul de covariance montrent qu'elles ne diffèrent pas significativement.

Les valeurs de solubilité azotée globale brute en milieu pepsine $-\mathrm{HCl}$ au $\mathrm{pH}$ 1,7 avec agitation durant $20 \mathrm{~h}$ à $45^{\circ} \mathrm{C}$ en présence de $50 \mathrm{mg}$ d'enzyme (pouvoir 200) sont légèrement inférieures aux coefficients d'utilisation digestive vraie; elles sont du même ordre pour les trois produits $(89,7-90,1-90,8)$.

Ainsi, les tests in vivo sur le porc et in vitro ne font ressortir aucune action spécifique des traitements technologiques tels qu'ils ont été appliqués pour cet essai, sur l'efficacité azotée des farines de harengs séchées à la flamme. 


\section{TABLEAU 1}

Coefficients d'utilisation digestive réelle (C.U.D.R.) et valeurs biologiques des 3 farines de harengs

$\left(60^{\circ}, 90^{\circ}, 130^{\circ}\right)$.

C. U. D. R.
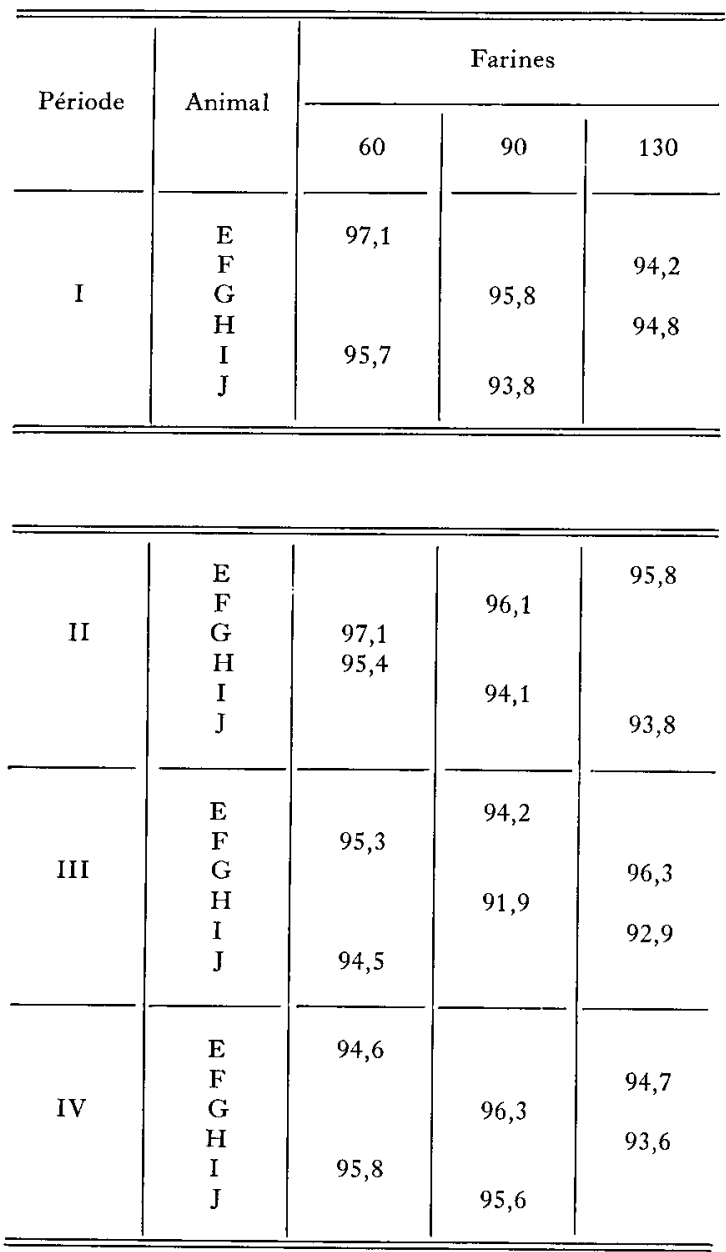

Valeurs biologiques
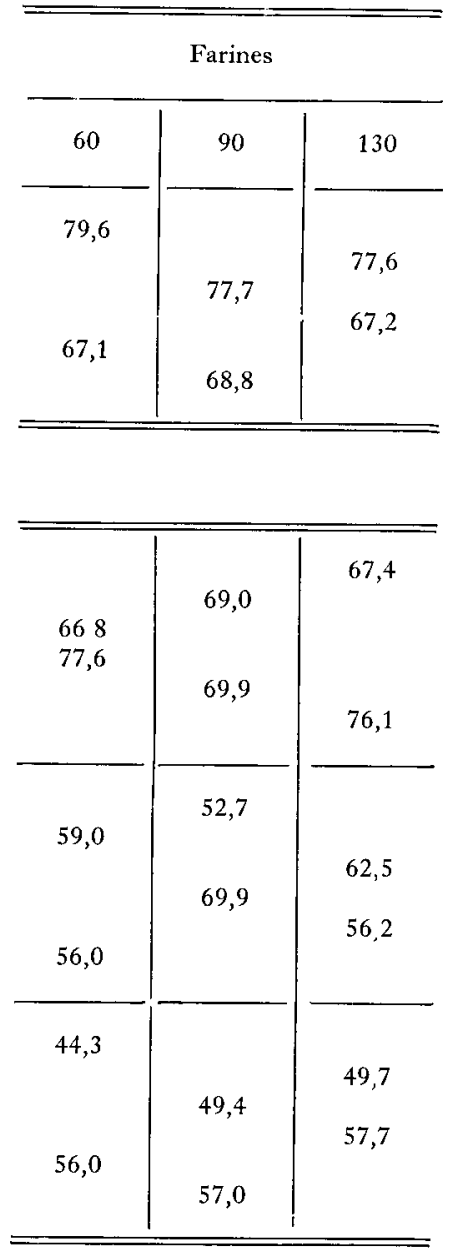

\begin{tabular}{l|l|l}
\hline 60,0 & 61,3 & 61,6 \\
\hline
\end{tabular}

